\title{
ARGUMENTAÇÃO E LÉXICO NA PERSPECTIVA DA ICONICIDADE VERBAL
}

André Conforte (UERJ/SELEPROT)

Resumo: Partindo do pressuposto de que o léxico, como parte concreta da linguagem, é capaz de construir cenários e mundos por meio de sua competente ativação no texto, e que a elaboração de campos semânticos é fator de alta iconicidade isotópica, este artigo visa demonstrar, por meio da análise de dois artigos que versam antagonicamente acerca do mesmo tema, usos lexicais que confirmam as hipóteses acima pressupostas. A escolha do texto argumentativo se dá pelo fato de que nosso objetivo é demonstrar, principalmente, como um bom manejo do léxico que o sistema da língua nos coloca à disposição, a par de outras estratégias, tem forte poder de persuasão e, portanto, é fator de grande eficácia na construção do texto argumentativo.

Palavras-chave: Léxico; Iconicidade lexical; Texto argumentativo.

Abstract: Based on the assumption that the lexicon, as a concrete part of language, is able to construct scenarios and worlds through its competent activation in the text, and that the elaboration of semantic fields is a factor of high isotopic iconicity, this article aims to demonstrate, by analising two articles which deal with the same subject, lexical uses that confirm the above-mentioned assumptions. The choice of argumentative texts was made once our objective is to demonstrate, mainly, how good management of the lexicon which the language system turns available to us, along with other strategies, presents strong persuasion power and, therefore, is a feature of great effectiveness in the construction of the argumentative text.

Keywords: Lexicon; Lexical iconicity; Argumentative text.

\section{INTRODUÇÃO}

O assim chamado modo argumentativo de organização do discurso (CHARAUDEAU, 2008), ao contrário do descritivo e do narrativo, deve ser estudado numa dimensão que se 
estende para muito além de uma mera tipologia textual. Não resta dúvida de que, em certo sentido, este modo não está num paralelo exato com os demais, e sua abordagem deve levar em conta pelo menos, para além da dimensão textualdiscursiva, ainda, os aspectos: a) retórico; b) dialético; c) lógico; e d) linguístico. Não é escopo deste artigo tratar de cada um desses planos, mas basta lembrar que se, por exemplo, num estudo sobre Argumentação, tratarmos de aspectos como o emprego de figuras de linguagem, período tenso (prótase/apódose) etc., estaremos privilegiando o aspecto a); se mencionarmos termos como tese/antítese/ síntese, estaremos nos centrando no aspecto b); se trabalharmos com a existência de silogismos, sofismas, paralogismos e falácias, estaremos nos situando no plano c); e, se analisarmos o papel dos operadores argumentativos, índices de pressuposição, modalizadores etc., nosso foco será o aspecto d). É claro que, em maior ou menor grau, todos esses planos se imbricam e podem comparecer juntos num estudo mais abrangente, como o de Marques (2011). De qualquer forma, já se disse alhures que não há, propriamente, uma teoria da Argumentação, mas sim teorias da Argumentação, e, no limite, é bastante conhecido o embate entre os lógicos e os retóricos (PERELMAN; TYTECA, [1958] 2005) na história das teorias argumentativas. 
Este artigo, entretanto, tem ambições bem modestas e visa estudar o texto argumentativo por meio de um aspecto que, no mais, é pouco abordado em boa parte dos estudos linguísticos: a seleção lexical. Partimos da ideia de que, num texto argumentativo, o léxico ${ }^{1}$ é capaz de construir cenários propícios à adesão de determinada tese. Como sabemos, num texto, as palavras não se dispõem isoladamente (referimo-nos, aqui, ao eixo paradigmático mesmo, não ao sintagmático), antes se irmanam, compõem um conjunto harmonioso que, devidamente engendrado, apresenta grande eficácia. Como nos lembra Garcia:

(...) as palavras se associam também por uma espécie de imantação semântica; muito frequentemente, uma palavra pode sugerir uma série de outras que, embora não sinônimas, com elas se relacionam, em determinada situação ou contexto, pelo simples e universal processo de associação de ideias, pelo processo de palavra-puxa-palavra ou de ideia-puxa-ideia. É o agrupamento por afinidade ou analogia, que poderíamos chamar de "campo associativo" ou "constelação semântica". (2010, p.197)

O estudo dos campos semânticos se mostra uma eficiente ferramenta didática quando conseguimos aliar léxico e discurso. Nosso artigo procurará demonstrar, de maneira bastante direta, 1 Já adiantamos, aqui, que trataremos os termos: léxico e vocabulário, não obstante as distinções adotadas em muitos estudos, como termos sinonímicos. 
como essa conjugação se aplica aos textos argumentativos com que nos deparamos em nossas leituras cotidianas. Para tanto, faremos uso de dois textos argumentativos cuja orientação se opõe em relação a um mesmo tema. Em seguida, procuraremos demonstrar como o que chamaremos de "manchas lexicais" se relaciona com as orientações argumentativas dos respectivos textos estudados.

\section{A ICONICIDADE LEXICAL}

Simões (2009) chama a atenção para o fato de que uma boa manipulação dos elementos lexicais estabelece uma comunicação mais eficaz, até mesmo por meio da ativação de processos cognitivos por parte do interlocutor. Para tanto, “o repertório amplo é condição para disponibilização de itens léxicos suficientes à expressão das ideias de forma icônica", e "a representação do pensamento será tão mais icônica quanto mais proficiente for o enunciador" (p.86); daí que não faz sentido, de fato, um processo de ensino/aprendizagem da língua que não promova a ampliação quantitativa e qualitativa do repertório lexical. Ainda segundo Simões:

(...) texto deverá produzir ícones e índices que permitirão ao interlocutor compreender o raciocínio do enunciador. Uma vez concluído, transforma-se em símbolo preferencialmente aplicável à interpretação de outros objetos similares. 
A descoberta de sentidos destaca a importância do domínio do vocabulário da língua, como também a competência de seleção dos significados mais adequados ao texto em foco. (2009, p.87)

Decorre em parte da iconicidade lexical a chamada iconicidade isotópica, responsável pela manutenção temática do texto, por meio de procedimentos de recorrência dentre os quais nos interessa destacar, aqui, o estabelecimento de campos semânticos coesos. Essa espécie de iconicidade

(...) se faz no rastreamento de palavras e expressões que possam sustentar esse ou aquele tema. A garantia dos recortes isotópicos propostos para esse ou aquele texto se assenta exatamente na possibilidade de identificação de itens léxicos (palavras ou expressões) que constituam campos lexicais ou campos semânticos que ratifiquem a opção temática proposta. (SIMÕES, 2009, p.89)

\section{OS TEXTOS E O CONTEXTO}

Os dois textos selecionados foram publicados há dez anos no jornal Folha de S. Paulo, e discutiam o então candente assunto "Força de paz brasileira no Haiti". O contexto era o seguinte: naquele momento, após a deposição do presidente Jean-Bertrand Aristide, o Haiti vivia um processo de verdadeira convulsão social, de modo que o Brasil, que tinha ambições de conseguir um assento permanente no Conselho 
de Segurança da ONU, foi instado a enviar uma força de paz para aquele país. Como estratégia inicial de aproximação, até mesmo a Seleção Brasileira de futebol realizou uma partida na capital, Porto Príncipe, e os soldados brasileiros foram a princípio muito bem recebidos pelo povo local.

No entanto, com o passar do tempo, em meio à terrível instabilidade econômica, social e institucional, a relação entre as tropas brasileiras e parte da população local começou, como seria natural, a sofrer desgastes, e, no dia 07 de janeiro de 2006, o general que comandava a força de paz, Urano Bacellar, foi encontrado morto na suíte do hotel em que se hospedava. A hipótese inicial dava conta de que ele havia se suicidado².

A morte do general causou grande comoção, e não tardaram os questionamentos sobre a presença das tropas brasileiras no país caribenho. No calor da polêmica, o periódico paulistano, na sua seção intitulada "Tendências/ Debates", na pág. 02, lançou a seguinte questão: “O Brasil deve continuar a missão no Haiti?". Para o debate, foram chamados dois especialistas no assunto: defendendo a permanência da força de paz, escreveu o embaixador

2 Entretanto, vazamentos posteriores do Wikileaks levantaram fortes suspeitas de que o general fora, de fato, assassinado. A discussão foge ao escopo deste artigo, mas, de qualquer forma, remetemos o leitor à fonte de tal informação, em inglês: https://www.theguardian.com/ commentisfree/cifamerica/2011/jan/21/haiti-wikileaks?INTCMP=SRCH. 
Gonçalo de Barros Carvalho e Mello Mourão, diretor do Departamento da América Central e Caribe do Itamaraty; defendendo posição diametralmente oposta, escreveu o já falecido deputado federal João Hermann Neto (PDT-SP), então membro da Comissão de Relações Exteriores e Defesa Nacional da Câmara dos Deputados.

Um primeiro fator discursivo a se considerar, e que se associará, evidentemente, à escolha lexical (assim como às demais estratégias argumentativas) de cada um dos contendores, é a posição institucional, o lugar de fala que ambos ocupam naquele momento: como embaixador brasileiro, caberá a Gonçalo Mourão defender, dentro da margem de manobra permitida pelo contrato de comunicação do domínio discursivo diplomático, as posições institucionais do governo brasileiro de então; já Hermann Neto, por sua vez, na condição de deputado de um partido que, naquele momento, fazia oposição ao governo Lula, encarnava, obviamente, o discurso contrário. Esses fatores aparentemente externos aos textos são de suma importância para que se faça uma correta análise deles. Reproduzamos, portanto, cada um dos artigos, para que possamos proceder, em seguida, à análise de cada um em separado. 


\section{TEXTO 1: SIM}

\section{SOLIDARIEDADE FRATERNA (GONÇALO MOURÃO)}

O Brasil foi ao Haiti com muito mais do que 1.200 soldados. Foi com o propósito de contribuir decididamente para a promoção da estabilidade política e do desenvolvimento econômico com justiça social em um país cada vez mais próximo de nós, à medida que vamos saldando a extraordinária dívida de séculos de desconhecimento e distanciamento. O contato com a população haitiana nos ajuda a confrontar nosso próprio passado: boa parte dos brasileiros afrodescendentes vieram do antigo Daomé (atual Benin), de onde descendem majoritariamente os haitianos.

O Haiti foi o primeiro país a ficar independente na América

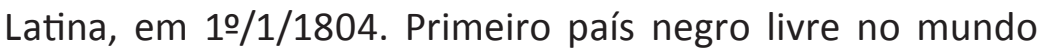
moderno, sua independência foi passo decisivo numa busca dramática pela liberdade, que continua até hoje.

O Brasil foi ao Haiti imbuído de um sentimento de solidariedade fraterna que o próprio Haiti, no continente americano, foi um dos primeiros a expressar. Seus próceres, logo após a independência, contribuíram para a libertação continental, financiando e aconselhando Miranda e Bolívar. Pediam apenas, em troca, a libertação dos escravos da América espanhola! Menos conhecido, e mais distante de nossa região, 
foi o episódio em que enviaram à Grécia um navio carregado de café em apoio a sua luta por independência. $\mathrm{O}$ bom café haitiano deu, assim, um exemplo de solidariedade que pode servir de inspiração em um cenário contemporâneo frequentemente marcado pela miopia do interesse no ganho imediato.

O mesmo espírito solidário inspira nossa presença no Haiti. Nossa atitude é diferente de esforços anteriores, que privilegiavam o uso da força. O Brasil não está lá para impor soluções sob a bandeira da ONU. Defendemos um esforço concentrado em favor da consolidação democrática e da reorganização institucional, econômica e social do país. A liberdade, hoje, se traduz na busca de soluções adaptadas às circunstâncias locais para a vigência de instituições democráticas sólidas e o desenvolvimento sustentável com justiça social.

Não nos iludamos. Nada é fácil no Haiti. O país mergulhou em anos de aviltamento que levaram até ao paradoxo do fenômeno cruel dos "boat people", grupos que, se sentindo desprovidos de um futuro em sua própria terra, não hesitam em arriscar a vida na busca de oportunidade alhures.

O Brasil deseja ver o Haiti integrado à família latinoamericana, abrindo oportunidades de cooperação que, somadas a outros esforços de doadores do mundo 
desenvolvido, ajudem os haitianos a reconstruir seu país. Muitos trabalharam e trabalham no Haiti para a implantação daquela sociedade livre, justa e digna que o país vem procurando desde o início de sua história, às vezes de maneira dramática. Muitos morreram, ou desistiram, mas a sociedade haitiana, por mais vulnerável e carente, continua a caracterizar-se por uma forte identidade nacional e por um anseio comovente por liberdade e desenvolvimento.

O general Urano Bacellar foi contribuir, generosamente, para este objetivo de uma sociedade mais próspera e justa, e seu desempenho no Haiti esteve sempre em estrita sintonia com o espírito que nos inspira a participar de uma missão inovadora de estabilização. Sua tragédia pessoal não pode desviar nosso país do movimento de solidariedade que nos levou até lá. Pelo contrário, a continuidade de nossa presença é uma demonstração de que estamos e estaremos, definitivamente, ao lado dos haitianos, no bom caminho, apesar das agruras. Desejamos que as eleições de 7 de fevereiro se realizem em ambiente de serenidade, abrindo caminho para que o Haiti saia da agenda do Conselho de Segurança da ONU e venha a transformar-se no primeiro item da recém-criada Comissão de Construção da Paz. 
O Haiti, como o Brasil, foi membro fundador da Liga das Nações. Às portas da Segunda Guerra Mundial, o exército italiano invadiu a Etiópia e, na Liga das Nações, o embaixador haitiano, representante da única nação negra ali, fez solitário e contundente protesto em solidariedade ao remoto país agredido. Condenou o imperialismo italiano e todos os imperialismos e lançou às demais nações uma advertência premonitória, que ainda hoje deve ecoar nos quatro cantos do mundo: "Temei de vir a ser um dia a Etiópia de alguém!".

O Brasil está no Haiti para ajudá-lo a encontrar o destino de liberdade e justiça atrás do qual sempre andou, no resgate dos séculos de desconhecimento e distanciamento que separaram nações essencialmente irmãs. É como se tivéssemos escutado, com ouvidos modernos, a advertência feita na Liga das Nações e desejássemos contribuir para que o Haiti se desenvolva econômica, social e institucionalmente e, em contraste com a Etiópia do pré-Segunda Guerra Mundial, se afirme como nação soberana e democrática integrada a seu entorno e à comunidade internacional.

Uma leitura atenta do texto de Mourão nos fará perceber que seu métier exerce grande influência na formulação de seus argumentos, já que diplomatas, por sua formação, têm elevado conhecimento histórico. Uma de suas estratégias, 
portanto, será evocar a ancestralidade comum entre brasileiros e haitianos, como já se vê no primeiro parágrafo, para incutir no leitor, sub-repticiamente, um sentimento de culpa por desconhecer o "irmão" caribenho. Essa mesma estratégia de inculcação de culpa, sempre com o apoio de dados históricos, se repetirá em outros momentos do artigo. No entanto, a alusão histórica do primeiro parágrafo já se coaduna com os vocábulos presentes no próprio título, que evocam dois campos semânticos a serem exaustivamente explorados ao longo de todo o texto: solidariedade (que nós, como brasileiros, temos a obrigação de prestar) e fraternidade (porque, afinal de contas, temos laços de consanguinidade com os haitianos). Sabemos do caráter englobante que os títulos, de um modo geral, possuem (de fato, a escolha de um bom título já é uma estratégia que pode imprimir alta iconicidade a um texto); portanto, todo o levantamento lexical deste artigo pode ser feito a partir destas duas "constelações semânticas", ambas de base meliorativa, como se pode constatar por meio de substantivos, adjetivos, advérbios, verbos e frases como abaixo:

contribuir decididamente, promoção, estabilidade, desenvolvimento, justiça social, próximo, contato, bom, espírito solidário, presença, esforço concentrado, 
consolidação democrática, reorganização institucional, econômica e social, liberdade, soluções, instituições democráticas sólidas, desenvolvimento sustentável, integrado à família latino-americana, oportunidades de cooperação, esforços de doadores, ajudem, reconstruir, trabalharam e trabalham, implantação daquela sociedade livre, justa e digna, forte identidade nacional, anseio comovente por liberdade e desenvolvimento, contribuir, generosamente, sociedade mais próspera e justa, estrita sintonia, espírito, inspira, participar, missão inovadora de estabilização, movimento de solidariedade, continuidade de nossa presença, definitivamente, ao lado dos haitianos, no bom caminho, desejamos, ambiente de serenidade, abrindo caminho, ajudá-lo, destino de liberdade e justiça, contribuir, se desenvolva econômica, social e institucionalmente, se afirme, nação soberana e democrática, integrada a seu entorno e à comunidade internacional.

Por meio desse levantamento lexical primário, foi possível mapear o texto de forma a rastrear todos os signos indicadores de traços semânticos eufóricos em relação à permanência da força de paz brasileira no Haiti. Se, por convenção, marcarmos de amarelo todos os itens lexicais e fraseológicos meliorativos do texto de Gonçalo Mourão, 
teremos a seguinte configuração gráfica:

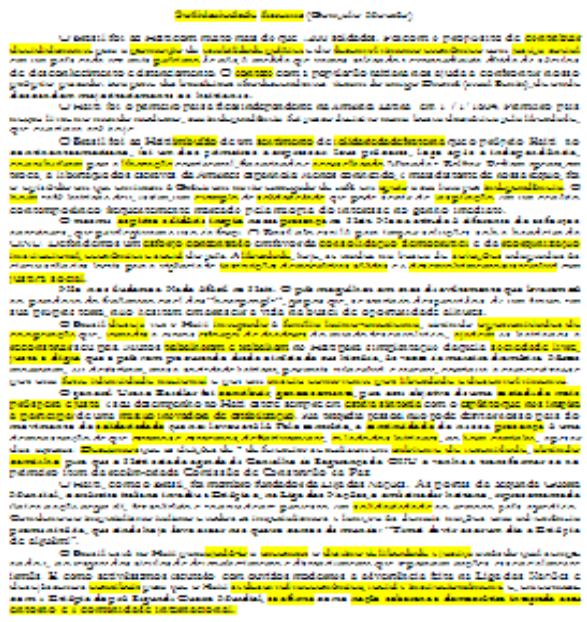

Nota-se que a mancha amarela percorre praticamente todo o texto, deixando de cobrir somente alguns pequenos trechos. Resta saber por que determinadas porções escapam dessa mancha meliorativa. Constatamos que isso se dá basicamente por duas razões:

a) ou estas porções, como índices de polifonia, são momentos de concessão, estratégia argumentativa que consiste em concordar parcialmente com os argumentos contrários, no intuito de trazê-los para o seu campo de argumentação e poder debater presencialmente com eles, preferencialmente refutando-os; nesse momento, o autor faz amplo uso de eufemismos para se referir à questões 
delicadas como o suposto suicídio ("tragédia pessoal", nas palavras de Mourão) do general Urano Bacellar ou o mesmo o conjunto de todos os acontecimentos ruins por que passava o país ("agruras"),

b) ou elas representam momentos de crítica aos que se opõem à ocupação; nesse caso, o vocabulário utilizado adota orientação contrária, por óbvio.

Façamos, então, uma segunda varredura do texto, assinalando em verde os momentos de concessão, marcados principalmente pelo emprego dos eufemismos. Agora teremos a seguinte configuração gráfica:

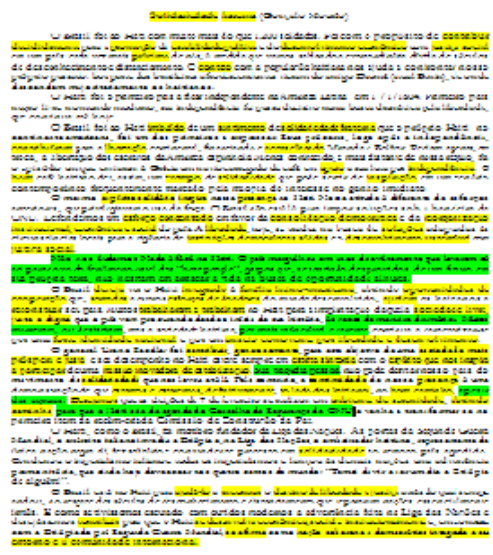

A mancha verde, que agora vemos, confirma o que se observa na maioria dos textos argumentativos prototípicos: o movimento de concessão/restrição se dá, de um modo geral, nos parágrafos intermediários, já que, próximo à conclusão, é 
aconselhável que o enunciador retome o seu ponto de vista, sob pena de acabar argumentando a favor do oponente.

Restam agora os trechos em que, principalmente, por meio de argumentos históricos, o autor dirige críticas aos que pensam de modo diferente; como é característico do discurso diplomático, essas críticas se farão por meio de um vocabulário comedido e polido, eivado de informações implícitas, mas com endereço certo. Convencionemos agora pintar de vermelho o vocabulário pejorativo do texto, que assume finalmente a seguinte configuração:

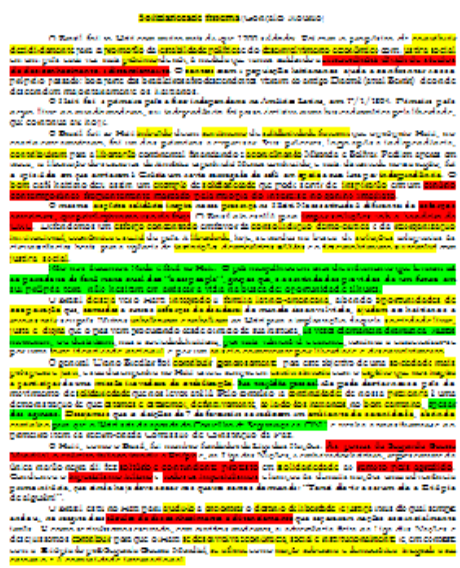

Após essa disposição cromática final, percebemos como o léxico se integra perfeitamente ao discurso, já que a diversidade de cores ecoa a diversidade de vozes, a polifonia propriamente dita do texto argumentativo. 


\section{TEXTO 2: NÃO}

\section{UM TIRO NO HAITI (JOÃO HERRMANN NETO)}

"O Brasil o tirou de mim"

(Maria Ignez Bacellar)

O Haiti foi a única nação negra liberta das Américas, teve um governo monárquico e independente e exibiu a mais próspera economia do Caribe. Hoje, vive nos EUA. Tornou-se uma nação desnutrida de povo. A maior fração de seus habitantes se autoexilou no continente. Os recursos enviados do estrangeiro pelos nativos constituem receita fundamental à economia miserável da ilha. No contraponto, muito do ilícito nacional é consentido pela conexão haitiana em solo americano. A burguesia negra ocupa um Everest social num relevo de miséria e, mancomunada com interesses estrangeiros, praticou regimes títeres, assassinatos em massa e, vil, fez do vodu uma arma tirânica.

O panorama social é escatológico. Trafegar entre sua gente nos mostra a inumanidade do nosso tempo. 0 panorama econômico é desértico e tem como moldura uma atividade laboral escravista. O panorama político é convulso e zerado institucionalmente. 
Nas diversas regiões do Haiti, a única certeza é a ausência do Estado. A dissolução das Forças armadas semeou militares armados e destituídos de comando. A polícia civil é escassa, esparsa e pastoreia a corrupção. O Judiciário entregou o chefe da Suprema Corte à autoridade presidencial nomeada do país e vive à bancarrota. O Executivo, implodido no seu intestino, não exibe burocracia confiável nem dispõe de recursos. A infraestrutura é colapsada: por exemplo, não se coleta lixo urbano nem se combate o fogo. A habitação popular é um cortiço. Para não corar, é de bom alvitre não falar em saúde e educação. O Legislativo aguarda eleições geridas pela incúria dos organismos estrangeiros, pela ausência completa de processo democrático e absenteísmo partidário.

A ausência de meios impede que uma presença militar se transforme numa força política de estabilização.

Nossa participação como Estado-membro da ONU não nos faz somente observadores mundiais. Neste estágio de Brasil potência-emergente é mister que assumamos nossas obrigações. Nossa inclusão organizacional não é apenas para presidente da República discursar na abertura dos trabalhos na esteira de Osvaldo Aranha, diplomatas exercerem com correção seus trabalhos nas atividades em que o Brasil se relaciona com seus parceiros ou parlamentares serem vistos em missões duvidosas de observadores em Nova York. 
Missões espinhosas também devem ser exercidas por um país como o nosso. Mesmo com risco material. Mesmo ao custo de vidas. A paz é axioma do nosso sentido de vida. A democracia, nosso único ponto cardeal. Missões de paz e a busca da democracia justificam nossa presença em qualquer canto do planeta.

Mas jamais participaremos de missões de guerra, de intervenção militar ou de ocupação nacional sob nenhum pretexto e em nenhum tempo. Este é justamente o momento com que nossa missão militar se defronta no Haiti, com 1.200 brasileiros - e um general morto.

Fomos em missão de paz. Eu, pelo voto, a autorizei. Sabia da complexidade, mas também da importância. Havia uma série de compromissos corolários à decisão autorizatória. Além do tempo de permanência outorgado pela ONU, previa-se um aporte vultoso de recursos vindos de nações desenvolvidas. Eram para prover o Haiti de compromissos com a cidadania. De prever seu crescimento e nivelar as disparidades. Para construir um modelo institucional que funcionasse minimamente, que desse condições imediatas de vida a seu povo, que lhes mostrasse, com esperança, o caminho da dignidade.

Tsunamis e Katrinas depois, nada aportou no Haiti, a não ser marés de desolação e furacões de turbulência social. 
O estado político no Haiti é hecatômbico e próspero cadinho para um cataclismo social. É previsível um futuro sombrio com repressões, mortes, vandalismo e autoritarismo. Nossos militares não podem se prestar a esse serviço. Não podemos assistir solertes a essa omissão mundial. Os países-membros da ONU não cumpriram sua palavra de ajuda ao Haiti. Sem esses recursos, é impossível promover a paz. Com a palavra quebrada, nossa presença se transformará numa intervenção militar.

Já que o mundo desenvolvido voltou as costas para o Haiti em nome de "outras grandes causas", o Brasil não pode ser conivente com essa injúria. Nossa herança diplomática defende a não intervenção e a autodeterminação dos povos. Continuar com a presença militar naquele país ameaça que se tornam verdadeiras as acusações de a estarmos fazendo a serviço de alguém ou da cátedra. Jamais a estaríamos fazendo a serviço da democracia e da paz mundial.

Que o general Urano tombe por uma nobre causa. Assim quiseram as palavras de sua viúva dizer. Que o Brasil o tire de nós para colocá-lo na história. Nunca na tirania!

O artigo de João Herrmann Neto lança mão de estratégias, ligeiramente, diferentes das adotadas por Gonçalo Mourão. A primeira delas, de forte apelo emocional, é colocar em 
epígrafe uma frase proferida pela própria viúva do general brasileiro morto no Haiti; uma segunda estratégia, que visa atingir a memória textual do leitor, se encontra no último parágrafo: trata-se de uma sutil referência intertextual, na verdade uma alusão (uma das formas mais sutis de intertextualidade) à célebre carta-testamento de Getúlio Vargas (lembremo-nos de que tanto o presidente quanto o general, em tese, se suicidaram); a estratégia aqui é elevar o general ao mesmo patamar histórico de Getúlio, martirizálo, ainda que inconscientemente.

Outra estratégia largamente utilizada por Herrmann Neto em seu artigo, agora já com o apoio do léxico pejorativo, é o uso da descrição a serviço da argumentação, na tentativa, a nosso ver bem-sucedida, de construir um cenário de "terra arrasada" do país ocupado pelas tropas brasileiras. Notaremos que, no artigo que analisaremos, não há propriamente a construção de campos semânticos muito específicos; a estratégia vocabular se centrará, agora, numa operação de predicação, de adjetivação bastante "carregada" do ponto de vista semântico. Tanto no aspecto quantitativo quanto qualitativo, o vocabulário orientado pró-tese será consideravelmente mais significativo do que o vocabulário que levantamos no primeiro artigo. Entendemos que a abundância 
de adjetivos caracteriza um texto menos centrado na razão e, consequentemente, com apelo mais forte à emoção. Segue o levantamento lexical do segundo artigo:

nação desnutrida, autoexilou, economia miserável, ilícito, conexão haitiana, burguesia negra, miséria, mancomunada, interesses estrangeiros, regimes títeres, assassinatos em massa, arma tirânica, escatológico, inumanidade, desértico, escravista, convulso, zerado institucionalmente, ausência, dissolução, armados, destituídos, escassa, esparsa, pastoreia a corrupção, à bancarrota, implodido, não exibe burocracia confiável nem dispõe de recursos, não se coleta lixo urbano nem se combate o fogo (a negação é um recurso também bastante utilizado), colapsada, cortiço, é de bom alvitre não falar em saúde e educação (preterição, uma espécie de negação que acaba por afirmar), incúria, ausência completa, absenteísmo partidário, ausência de meios, impede, missões de guerra, intervenção militar, ocupação nacional, general morto, Tsunamis e Katrinas (metáforas negativas, como já foi o caso de cortiço), marés de desolação, furacões de turbulência social (metáforas em paralelismo com "Tsunamis e Katrinas"), hecatômbico, cataclismo social, futuro sombrio, repressões, mortes, vandalismo e autoritarismo, omissão mundial, impossível, palavra quebrada, intervenção militar, voltou 
as costas, "outras grandes causas" (uso de aspas indicando ironia), conivente, injúria, ameaça (v.), acusações, a serviço de alguém ou da cátedra (insinuação maliciosa), tirania.

Seguindo-se o mesmo modelo semiótico utilizado para o primeiro artigo, mas invertendo a ordem, ou seja, começando pela cor vermelha, teríamos a seguinte configuração gráfica:

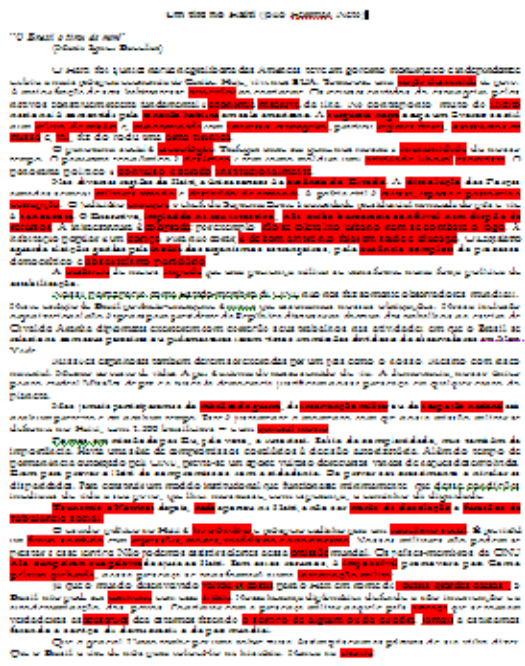

A observação da mancha vermelha, representando o vocabulário pejorativo empregado pelo deputado do PDT, nos revela um fato curioso: há pelo menos duas significativas porções do texto em que essa mancha não aparece; observando o conteúdo desses trechos, verificamos que elas consistem em dois momentos de concessão, que, no entanto, fazem uso de estratégias diferentes entre si 
e também diferentes da estratégia eufemística utilizada pelo artigo de Gonçalo Mourão. Nos dois parágrafos bem no meio do texto, Herrmann Neto reconhece, de fato, que países inseridos no contexto mundial devem participar de missões de paz. No entanto, o processo de referenciação da presença das tropas brasileiras no Haiti é afirmado no parágrafo em que a mancha vermelha reaparece, por meio da refutação operada pelo operador argumentativo mas, introdutor dos argumentos pró-tese, que recategorizam a presença militar como uma intervenção, e não como uma missão de paz.

Já no parágrafo que se inicia com "fomos em missão de paz", o deputado parece recorrer a uma estratégia de proteção de face, uma vez que, como reconhece, ele mesmo votou a favor do envio das tropas. Então, vê-se obrigado a fazer mea culpa, utilizando, como justificativa, o fato de haver promessas e condições não cumpridas para justificar sua mudança de opinião. Para tanto, emprega os verbos no pretérito imperfeito do indicativo e do subjuntivo, com o intuito de indicar fatos que não se realizaram (havia, previase, eram, desse, mostrasse).

Vejamos, portanto, como a mancha amarela aparece no texto em análise: 


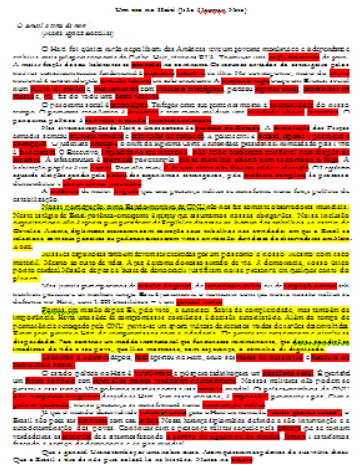

Por fim, poderemos empregar a mancha verde do texto nas suas primeiras linhas, em que, com o emprego de verbos no pretérito perfeito do indicativo (significando algo que se deu pontualmente no passado e é um processo já terminado), o autor faz escassos elogios ao Haiti. Esta seria, portanto, a disposição cromática final do texto:

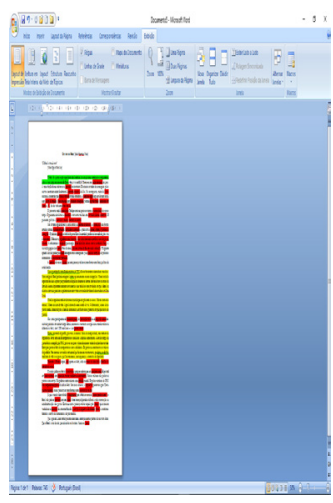

Por fim, podemos reforçar a hipótese (embora mais ou menos consensual, como já dissemos) de que a seleção vocabular (entre outros aspectos da linguagem, é claro) 
constrói cenários, fazendo uma comparação entre a forma como cada texto projeta o futuro do Haiti. Vejamos, apenas a título de comparação, como os textos 1 e 2 constroem esse cenário:

1) O Brasil deseja ver o Haiti integrado à família latinoamericana, abrindo oportunidades de cooperação que, somadas a outros esforços de doadores do mundo desenvolvido, ajudem os haitianos a reconstruir seu país. (...) Desejamos que as eleições de 7 de fevereiro se realizem em ambiente de serenidade, abrindo caminho para que o Haiti saia da agenda do Conselho de Segurança da ONU e venha a transformar-se no primeiro item da recém-criada Comissão de Construção da Paz.

2) É previsível um futuro sombrio com repressões, mortes, vandalismo e autoritarismo. (...) Com a palavra quebrada, nossa presença se transformará numa intervenção militar.

\section{CONCLUSÃO}

Não há maneira mais produtiva de demonstrar a eficácia das palavras do que por meio da verificação de seu funcionamento em contexto, em textos dos mais diversos gêneros. No entanto, em tempos de tanta exigência de redações vazadas quase que exclusivamente no modo argumentativo, é necessário que estudemos estratégias que não se limitem 
a chavões e regras pré-formatadas: a leitura comentada de bons textos argumentativos, que lancem mão de estratégias como as que analisamos acima, ainda nos parece ser o melhor caminho. E como no campo da Argumentação o léxico ainda não parece dispor de uma posição privilegiada, achamos por bem relevá-lo em nosso breve estudo. Esperamos que seja útil aos docentes e pesquisadores que se debruçam sobre essa modalidade textual.

\section{REFERÊNCIAS}

CHARAUDEAU, Patrick (2008). Linguagem e discurso: modos de organização. São Paulo: Contexto.

Folha de São Paulo (2006). Seção Tendências/debates. Edição de 15 de janeiro.

GARCIA, Othon Moacyr (2010). Comunicação em prosa moderna. Rio de Janeiro: Ed. da FGV.

MARQUES, Maria Aldina (2011). "Argumentação e(m) discursos". In: DUARTE, Isabel Margarida; FIGUEIREDO, Olívia (Orgs.). Português, língua e ensino. Porto: Editora da Universidade do Porto.

PERELMAN, Chaïm; OLBRECHTS-TYTECA, Lucie (2005). Tratado da Argumentação: a Nova Retórica. São Paulo: Martins Fontes.

SIMÕES, Darcilia (2009). Iconicidade verbal: teoria e prática. Rio de Janeiro: Dialogarts.

André Conforte é bacharel e licenciado em Letras (português/alemão) pela Universidade do Estado do Rio de Janeiro (2004), mestre em Língua Portuguesa pela Universidade do Estado do Rio de Janeiro (2007), tendo defendido a dissertação "As metalinguagens do samba", e doutor em Língua Portuguesa pela Universidade do Estado do Rio de Janeiro (2011), tendo defendido a tese "A esfinge clara em prosa moderna: a 
contribuição de Othon M. Garcia aos estudos linguísticos, textuais e literários". Atualmente é professor da graduação, categoria adjunto, na Universidade do Estado do Rio de Janeiro. Atua principalmente nos seguintes temas: letras de samba, gêneros textuais, metalinguagem, metadiscurso, interdiscurso e intertextualidade, produção textual e análise estilística.

Recebido em 01 de agosto de 2016. Aprovado em 28 de setembro de 2016. 